\title{
Experimental and Modeling Study on Reduction of Hematite Pellets by Hydrogen Gas
}

\begin{abstract}
MANIA KAZEMI, MOHSEN SAFFARI POUR, and DU SICHEN
Gaseous reduction by hydrogen was performed for three types of hematite pellets, two from industry and one prepared in the laboratory. The reduction mechanisms of the pellets were studied based on the morphologies of the partially reduced samples. Two mechanisms were found, the mechanisms of the two types of industrial pellets being very similar. The degree of reduction was followed as a function of time for each type of pellets. On the basis of the reaction mechanism of the industrial pellets, a mathematical model was developed. As a pioneer effort, the model combined the computational fluid dynamics approach for the flow and mass transfer in the gas phase with model of gas diffusion in the solid phase as well as the description of the chemical reaction at the reaction sites. The calculation results agreed well with the experimentally obtained reduction curves. The present work also emphasized the importance of evaluation of the reduction mechanisms and the properties of different types of iron ore pellets prior to developing a process model. While the present approach has established a good foundation for the dynamic modeling of the shaft reactor, more efforts are required to accomplish a realistic process model.
\end{abstract}

DOI: $10.1007 / \mathrm{s} 11663-016-0895-3$

(C) The Author(s) 2017. This article is published with open access at Springerlink.com

\section{INTRODUCTION}

THE rising interests in application of direct-reduced iron (DRI) have given the researchers new challenges in this area. An important factor in production of DRI in industrial practice, such as MIDREX or HYL processes, is the dynamic control of the process in the reactors. This dynamic control along with optimization of the process is essential to ensure both smooth process operation and the quality of the products, for example the metallization degree and cementite fraction in the reduced pellets. In the counter-current reactors for direct reduction, the oxide pellets move downward from the top of the reactor facing the gas mixture injected from the lower part. The chemical potentials of the gaseous species and the temperature vary at different positions in the reactor. The chemical potentials of the species can also differ inside each pellet at a given position. Hence, an efficient dynamic control of the process and the quality of the products demands a realistic process model.

A number of modeling works can be found for reduction of single pellets through different mechanisms, and for multi-particle reduction processes. ${ }^{[1-16]}$ In a work by Bonalde et al., reduction kinetics of iron ore pellets were described by the grain model. ${ }^{[1]}$ Pure $\mathrm{H}_{2}$, pure $\mathrm{CO}$, and gas mixtures similar to MIDREX gas were used. Reduction by pure gases was controlled by a

MANIA KAZEMI, MOHSEN SAFFARI POUR, and DU SICHEN are with the Department of Materials Science and Engineering, Royal Institute of Technology, 10044 Stockholm, Sweden. Contact e-mail: sichen@kth.se

Manuscript submitted June 27, 2016.

Article published online January 3, 2017. mixed mechanism in the initial stages and was changed to diffusion controlled mechanism at later stages. When the gas mixtures were applied, reduction was controlled by a mixed mechanism during the whole process. The model considered the size of the particles and the porosity of pellets and the results were in good agreement with experimental data for reduction by $\mathrm{H}_{2}$. Tien and Turkdogan developed a mathematical model for the isothermal reduction of single iron oxide pellets by a single-phase reducing gas $\left(\mathrm{H}_{2}\right.$ or $\left.\mathrm{CO}\right) \cdot{ }^{[2]}$ They developed a two-zone and a three-zone model for pellets with different diameters. It was demonstrated that the three-zone model consisting of a metal layer, metaloxide layer, and oxide core could describe the reduction of pellets used in direct reduction process. Kinetic models for gaseous reduction of single pellets with shrinking core or grain model have also been studied by other researchers. ${ }^{[3-6]}$

The reduction zone of the shaft furnace in MIDREX process was simulated by Parisi and Laborde. ${ }^{[7]}$ The unreacted shrinking core model was applied to the pellets. The process model developed assuming plug flow in the reactor was validated by data from two industrial plants and was found useful to predict the effects of different operation conditions on the process. Ranzani da Costa et al. simulated the reduction in a shaft furnace using hydrogen as the reductant. ${ }^{[8]}$ They developed and validated a kinetic model for pellets based on the laboratory results for reduction of small oxide particles. By applying the kinetic model in a model for a shaft reactor, the metallization degrees and the influences of different parameters were predicted. They concluded that the industrial hydrogen-based reduction process is feasible. A 2D model for reduction of iron ore 
pellets by $\mathrm{H}_{2}$-CO mixtures was developed by Ajbar et al. ${ }^{[9]}$ They applied the shrinking unreacted core model with 3 layers and the reduction reactions at the interfaces were considered reversible. The kinetics of steam reforming of methane and carburization were also considered. The reactor model was developed as a 1D steady-state moving bed considering plug flow reactor. They validated the process model by comparison of top gas analysis with the plant data. Shams and Moazenni developed a mathematical model for the MIDREX shaft furnace. ${ }^{[10]}$ They applied the shrinking core model to the reduction of pellets and considered the reactions in the reduction zone, transition zone, and cooling zone of the shaft furnace. The majority of the existing process models are developed for steady-state conditions; therefore, the changes occurring during the reduction process and furnace operation are not predictable by these models.

Preliminary studies in the present laboratory indicated that the reaction mechanisms could be different when different iron oxide pellets were used. Several authors have also reported that variations in the type of iron oxide pellets, grain size, porosity, and surface characteristics result in different reduction mechanisms. ${ }^{[1,17-21]}$ Large variations in the physical and chemical properties of iron ore pellets would limit the applicability of the existing process models to specific types of pellets and experimental conditions. Thus, a process model for direct reduction of iron oxide pellets requires consideration of the nature of the pellets, the local chemical potentials, and the local temperature.

The present work is the first step to develop a dynamic process model for direct reduction of iron ore pellets. The present model takes generality into consideration; in other words, it should be applicable to different types of commercial pellets with possible modifications of the chemical reaction and mass transfer properties according to the characteristics of the pellets. As the first phase of model development, the mechanisms of the reduction of 3 types of hematite pellets are studied. This identification is followed by quantifications of the parameters of mass transfer in the two types of industrial pellets. In the model, the mass transfer in the gas phase, the mass transfer in the pellet, and the chemical reaction rate are all considered. It is expected that this model can be used as a sub-model in a model for multi-particle system (e.g., pellet bed) in the next step.

\section{EXPERIMENTAL METHODS}

\section{A. Materials Preparation}

The reduction experiments were performed for two types of industrial iron ore pellets, namely type-I and type-II, and pure hematite pellets, named type-III. The average diameter of the pellets was between 11 and $12 \mathrm{~mm}$. The porosities of type-I and type-II samples were 26 and 34 pct, respectively. The hematite content in both industrial pellets was 96 pct and the pellets contained small amounts of nonferrous oxides such as $\mathrm{SiO}_{2}, \mathrm{CaO}$, and $\mathrm{MgO}$. The type-III samples were prepared to investigate the reduction of highly dense pellets. The pure pellets were made of analytical grade hematite powder and were sintered for 12 hours at $1273 \mathrm{~K}\left(1000{ }^{\circ} \mathrm{C}\right)$. The porosity of the pure iron oxide pellets was below 20 pct.

\section{B. Experimental Procedure}

The experiments were carried out isothermally in the setup illustrated in Figure 1. The experimental apparatus and the procedure were described in details in a previous publication. ${ }^{[21]}$ In each experiment, the sample was placed in the sample holder and the holder was connected to the balance by a stainless steel wire. After placing the sample in the water-cooled chamber, the setup was completely sealed and flushed with high-purity argon gas. All gas flow rates were controlled by mass flow meters. The reaction chamber was heated up until the target temperature was reached in the hot zone of the reaction tube. During heating, an argon atmosphere was maintained. When the temperature was stable, argon was replaced by hydrogen and the system was flushed with hydrogen gas with $2 \mathrm{~L} \mathrm{~min}^{-1}$ flow rate for 10 minutes to obtain a homogeneous atmosphere. The reaction was started by lowering the sample to the hot zone of the reaction tube. The movement was rather fast and took less than 5 seconds. The weight of the sample was recorded during reaction. When the reduction was complete, quenching was performed by lifting the sample rapidly to the cooling chamber and flushing the system by Ar gas with high flow rate. To investigate the reduction mechanism, a few samples were quenched when a certain degree of reaction was reached. The

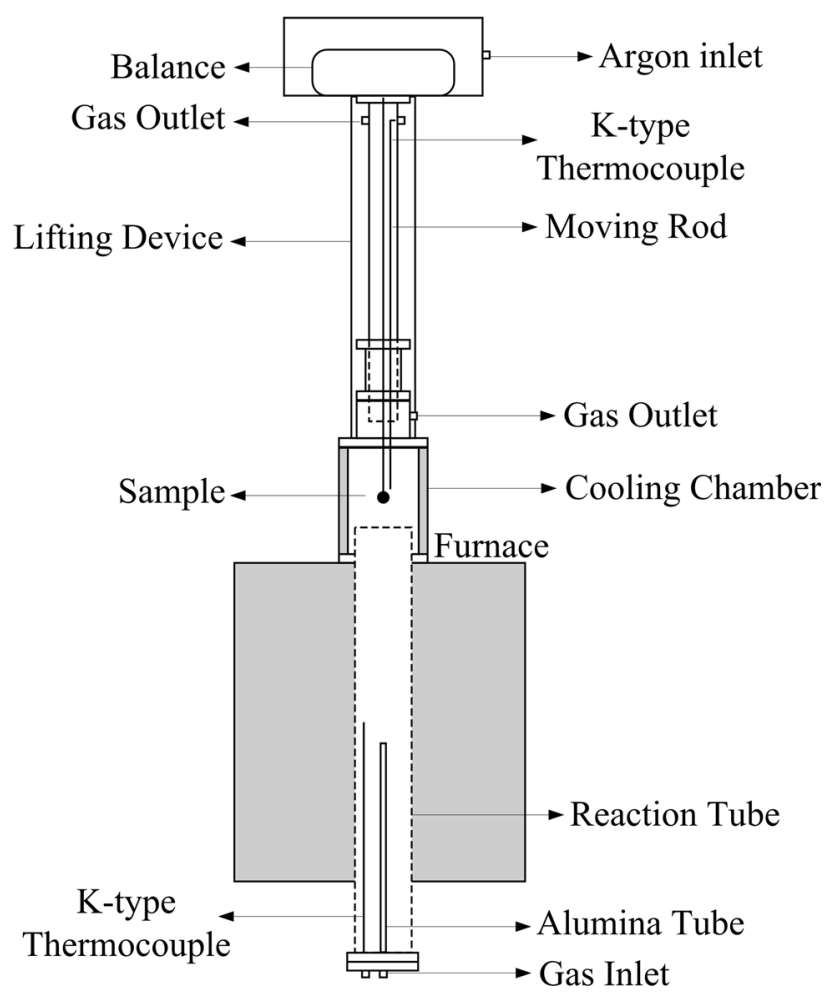

Fig. 1-Schematic illustration of the experimental setup. 
microstructures of partially and completely reduced samples were studied by SEM-EDS and LOM.

\section{EXPERIMENTAL RESULTS AND DISCUSSION}

\section{A. Mechanism of Reduction by Pure $\mathrm{H}_{2}$}

Reduction tests were carried out at $1073 \mathrm{~K}\left(800^{\circ} \mathrm{C}\right)$ and $1123 \mathrm{~K}\left(850^{\circ} \mathrm{C}\right)$. In all experiments, hydrogen gas with high purity was applied with a constant flow rate, namely $2 \mathrm{~L} \mathrm{~min}^{-1}$. The reduction mechanisms of three types of pellets were investigated by microscopic evaluation of the partially reduced samples. In the following presentation, the degree of reduction, $R_{\mathrm{ex}}$, is defined by Eq. [1].

$$
R_{\mathrm{ex}}=\frac{W_{0}-W_{t}}{W_{0}-W_{\infty}}
$$

where $W_{0}$ is the initial weight of the sample, $W_{t}$ is the weight of pellet at time $t$, and $W_{\infty}$ is the theoretical weight after complete reduction. Figure 2 illustrates the optical micrographs of the samples with partial reduction. Figure 2(a) and (b) shows type-I and type-II pellets with $R_{\mathrm{ex}}=0.2$. The micrographs in Figure 3 show the different areas in type-I sample reduced at $1073 \mathrm{~K}\left(800{ }^{\circ} \mathrm{C}\right)$. The thin outer layer around the pellet is mostly iron, and three different zones are observed in the inner parts of the sample (Figure 3(b) and (c)). Figure $3 b$ shows the layer consisting of wustite. The layer with two different oxide phases is shown in Figure 3(c). The core of the pellet is consisted of one oxide phase and is shown in Figure 3(d). The observed layers containing different phases indicate that the progress of reaction is being controlled by both internal gaseous diffusion and chemical reaction in the layers. At identical experimental conditions, reduction of type-II pellets took place with a similar mechanism.

The micrograph of type-III pellets is presented in Figure 2(c). The microstructure shows four distinct layers in the partially reduced sample, namely iron, wustite, magnetite, and hematite in the order from the surface towards the center of the pellet. High density of the pellet causes large resistance to mass transfer of gases to the reaction sites. As a result of different partial pressures of $\mathrm{H}_{2}$ inside the pellet, the reduction of hematite to iron takes place by intermediate stages of reduction to magnetite and wustite. The microstructure of samples clearly shows that the reduction mechanism of type-III pellets is different from the industrial samples.

Figure 4 represents the reduction curves of type-I and type-II pellets at $1073 \mathrm{~K}\left(800^{\circ} \mathrm{C}\right)$ and $1123 \mathrm{~K}\left(850{ }^{\circ} \mathrm{C}\right)$. In all types of samples, the rate of reduction increased at higher temperatures.

\section{B. Discussion}

It is well known that the reduction of sintered pellets by gases involves the following main steps:

(1) Mass transfer in the gas phase;

(2) Mass transfer through the product layer;

(3) Chemical reaction at the product/oxide interface.

In view of the different steps involved in the process, developing a process model requires careful identification of the reduction mechanisms. The micrographs of the partially reduced samples in Figure 2 evidently show that the reduction of type-III pellet has a different mechanism from the other two types. Since the model is aimed at industrial pellets, the development of the present model is focused on the type-I and type-II pellets. The morphology shown in Figure 2 indicates that the product layer (the outer layer) contains very small fraction of FeO. Hence, a model assuming moving reaction front is reasonable.

In most of the existing models, simplifications are made and kinetic data from different sources are used. ${ }^{[1-16]}$ Usually, the mass transfer in the gas phase is evaluated by dimensionless numbers. The use of dimensionless numbers in the reactor would be very difficult, because of the turbulent nature of the bed, the variation of the gas composition, and the variation of temperature. It is worthwhile to use the well-developed
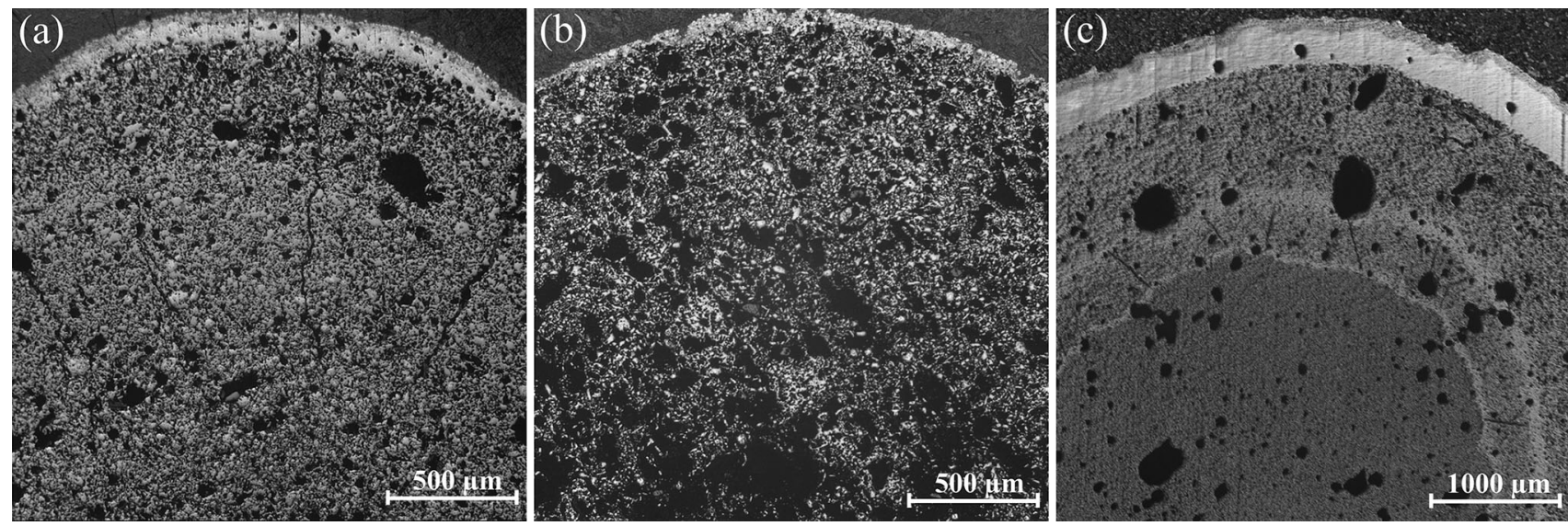

Fig. 2-Optical micrographs of hematite pellets, $Q=2 \mathrm{~L} \mathrm{~min}^{-1}$; $T=1123 \mathrm{~K}\left(850^{\circ} \mathrm{C}\right),(c)$ type-III, $R_{\mathrm{ex}}=0.5, T=1123 \mathrm{~K}\left(850^{\circ} \mathrm{C}\right)$.

(a) type-I, $R_{\mathrm{ex}}=0.2, \quad T=1073 \mathrm{~K}\left(800^{\circ} \mathrm{C}\right), \quad(b)$ type-II, $R_{\mathrm{ex}}=0.2$, 

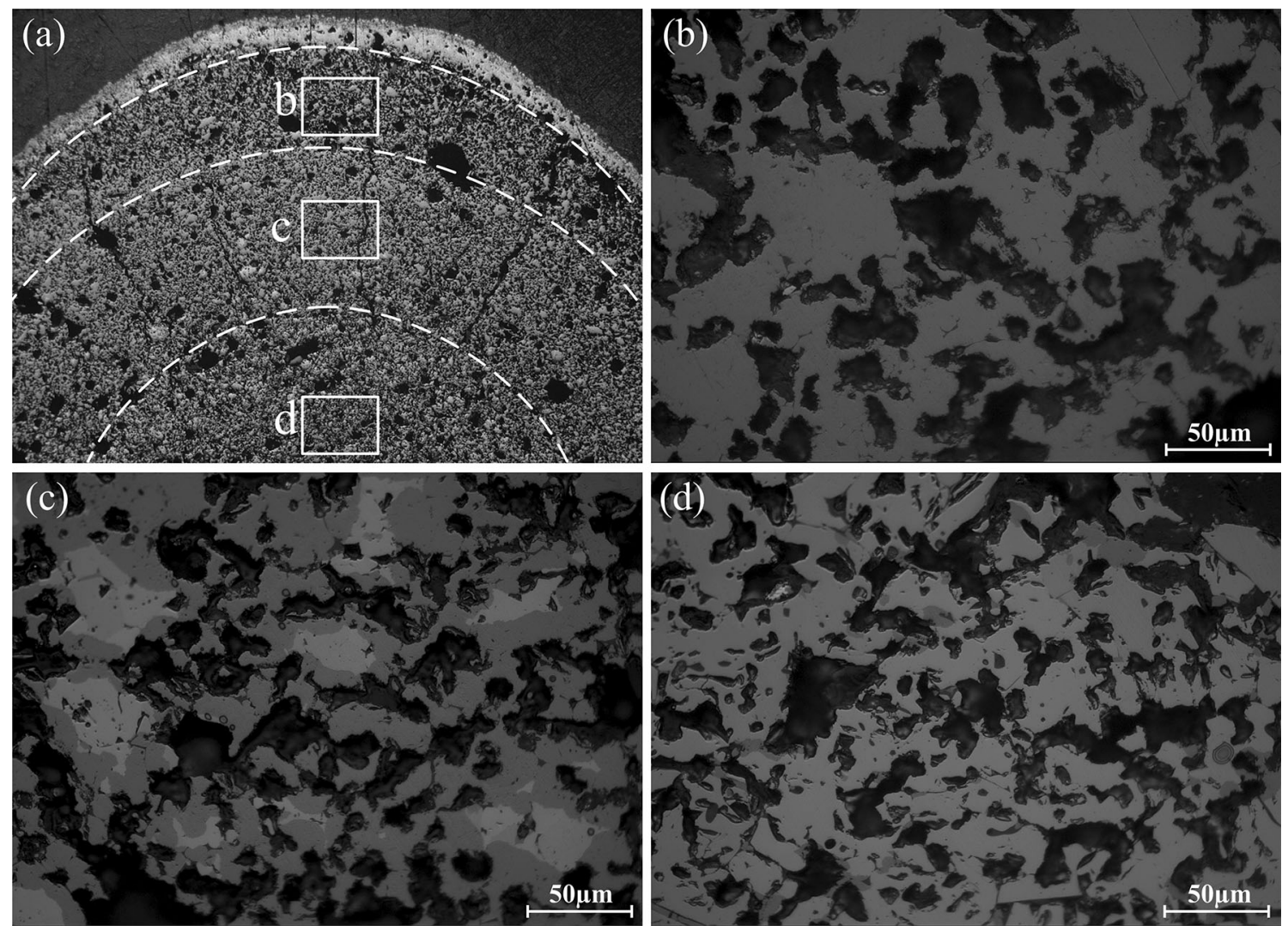

Fig. 3-Optical micrographs of type-I pellet, $R_{\mathrm{ex}}=0.2, T=1073 \mathrm{~K}\left(800^{\circ} \mathrm{C}\right), Q=2 \mathrm{~L} \mathrm{~min}{ }^{-1}$; $(a)$ different zones in partially reduced pellet, $(b)$ FeO layer, (c) layer containing different oxides, $(d)$ oxide core.

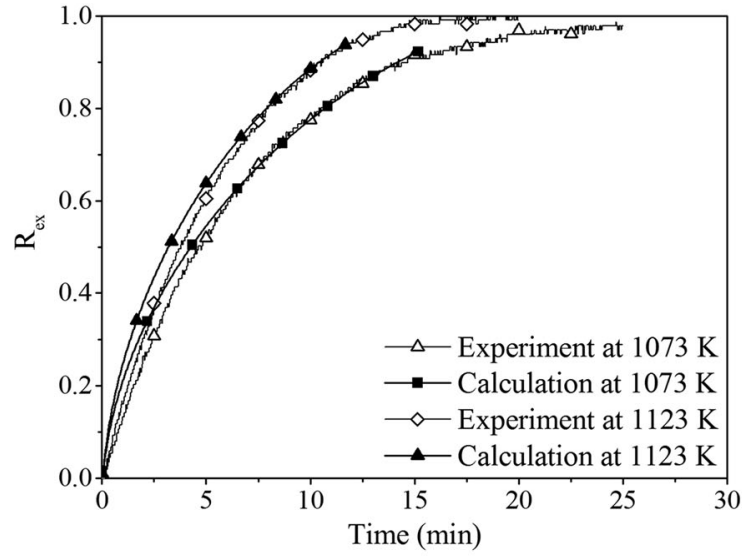

(a)

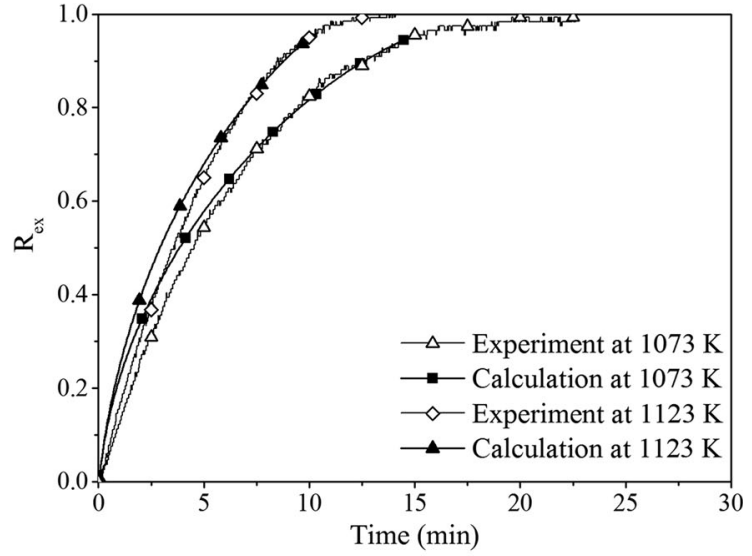

(b)

Fig. 4 -The reduction curves at $1073 \mathrm{~K}\left(800{ }^{\circ} \mathrm{C}\right)$ and $1123 \mathrm{~K}\left(850^{\circ} \mathrm{C}\right), Q=2 \mathrm{~L} \mathrm{~min}^{-1}$; (a) type-I, (b) type-II.

computational fluid dynamics (CFD) approach for calculating the flow and mass transfer in the gas phase. Although this calculation might not be necessary for a single pellet, it is absolutely essential for a shaft furnace. In the existing models, the chemical reaction rates are very often assumed fast. This assumption would also be questionable if the model is used for a shaft reactor, especially when porous pellets are used. The temperature varies extensively along the height. At lower temperatures, a mixed control of the 3 above-mentioned steps need to be considered. It should be mentioned that the rate of chemical reaction depends on the chemical composition of the gas phase (the chemical potentials of the species). This dependence further emphasizes the need to consider all the 3 steps in the reactor model.

\section{MATHEMATICAL MODELING}

A model for the reduction of iron oxide pellets by hydrogen was developed considering the mass transfer and chemical reaction steps involved in the reduction of a single 
pellet. The 2D axisymmetric model was developed in COMSOL Multiphysics 5.1 software. ${ }^{[22]}$ This model could be later applied in a multi-particle process model to predict the atmosphere composition in the furnace and the metallization degree of the DRI under different conditions.

As mentioned above, considering the importance of the industrial iron ore pellets, the model was based on the mechanism observed in the type-I and type-II samples. The following assumptions were made:

1. The temperature is constant in the model and is equal to the reduction temperature.

2. The density of the gas is constant.

3. The porosity of the solid and the effective diffusivity do not change with time.

4. The chemical reaction takes place isothermally and it is expressed by Eq. [2].

$$
\frac{1}{3} \mathrm{Fe}_{2} \mathrm{O}_{3}+\mathrm{H}_{2} \rightarrow \frac{2}{3} \mathrm{Fe}+\mathrm{H}_{2} \mathrm{O}
$$

5. The presence of small amounts of oxide in the outer layer is neglected and the layer is approximated as pure iron.

\section{A. The Model Domains}

The model domains are illustrated in Figure 5. The model consists of solid and gaseous phases.

The gas phase consists of $\mathrm{H}_{2}$ and produced $\mathrm{H}_{2} \mathrm{O}$. The flow in the gas phase is governed by the equations of continuity and conservation of momentum (Eq. [3] through [5]).

Continuity equation

$$
\frac{\partial \rho}{\partial t}+\frac{1}{r} \frac{\partial}{\partial r}\left(\rho r v_{r}\right)+\frac{\partial}{\partial z}\left(\rho v_{z}\right)=0 .
$$

Momentum equations r-component:

$\rho\left(\frac{\partial v_{r}}{\partial t}+v_{r} \frac{\partial v_{r}}{\partial r}+v_{z} \frac{\partial v_{r}}{\partial z}\right)=-\frac{\partial P}{\partial r}-\left(\frac{1}{r} \frac{\partial}{\partial r}\left(r \tau_{r r}\right)+\frac{\partial \tau_{r z}}{\partial z}\right)$.

z-component:

$\rho\left(\frac{\partial v_{z}}{\partial t}+v_{r} \frac{\partial v_{z}}{\partial r}+v_{z} \frac{\partial v_{z}}{\partial z}\right)=-\frac{\partial P}{\partial z}-\left(\frac{1}{r} \frac{\partial}{\partial r}\left(r \tau_{r z}\right)+\frac{\partial \tau_{z z}}{\partial z}\right)$.

In the gas phase, mass transfer due to convection and diffusion are considered and the mass transfer is governed by the mass balance equation (Eq. [6]). ${ }^{[23]}$

$$
\frac{\partial c}{\partial t}+\left(v_{r} \frac{\partial C}{\partial r}+v_{z} \frac{\partial C}{\partial z}\right)=D\left[\frac{1}{r} \frac{\partial}{\partial r}\left(r \frac{\partial C}{\partial r}\right)+\frac{\partial^{2} C}{\partial z^{2}}\right] .
$$

The solid phases refer to the product layer and the unreduced core in the pellet. The mass transfer of gases in the solid is described by the diffusive fluxes of $\mathrm{H}_{2}$ and $\mathrm{H}_{2} \mathrm{O}$ shown in Eqs. [7] and [8].

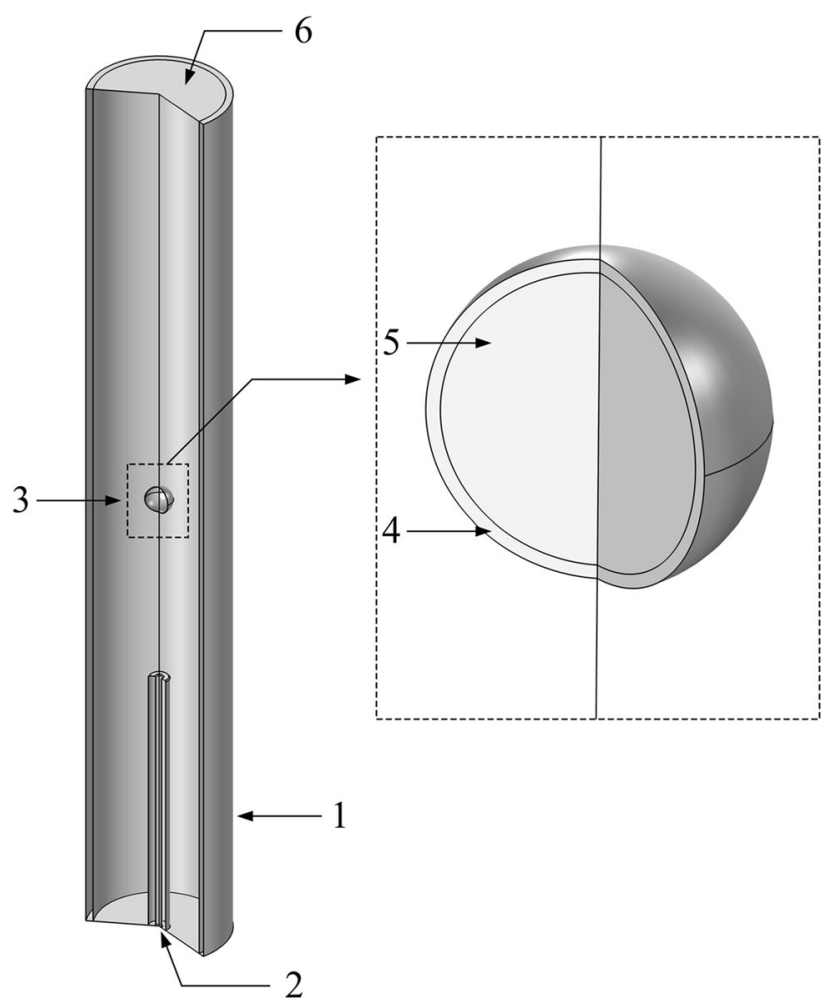

Fig. 5-The calculation domains: 1 reaction tube, 2 gas inlet, 3 pellet, 4 reacting layer, 5 oxide core, and 6 gas outlet.

$$
\mathrm{N}_{\mathrm{H}_{2}}=-A D_{\mathrm{eff}, \mathrm{H}_{2}} \frac{\mathrm{dC}_{\mathrm{H}_{2}}}{\mathrm{~d} r}
$$

$$
\mathrm{N}_{\mathrm{H}_{2} \mathrm{O}}=-A D_{\text {eff, } \mathrm{H}_{2} \mathrm{O}} \frac{\mathrm{dC}_{\mathrm{H}_{2} \mathrm{O}}}{\mathrm{d} r} .
$$

In Eqs. [7] and [8], $\mathrm{A}$ is the reaction surface area. It is evaluated at every calculation step using the location of the moving boundary (the inner radius). Due to the porous nature of the solid phases, the effective diffusion coefficients of gases in the solids was applied in the model. The effective diffusivity, $D_{\text {eff, }}$ is defined by Eq. [9]. ${ }^{[23]}$

$$
D_{\text {eff }}=D_{A} \frac{\omega}{\tau},
$$

where $D_{A}$ is the diffusivity of gas $A$; $\omega$ is the porosity of solid, and $\tau$ is the tortuosity factor which is determined by the structure of the solid. The porosity and tortuosity factor are specific characteristics of each type of pellet and are independent of the gas properties. For a given gas mixture, the effective diffusivity changes with the temperature and with the type of pellet.

\section{B. Boundary Conditions}

The gas has normal inflow velocity at the inlet where the volumetric flow rate of hydrogen is equal to $2 \mathrm{~L} \mathrm{~min}{ }^{-1}$. At the gas outlet, the pressure is set to 


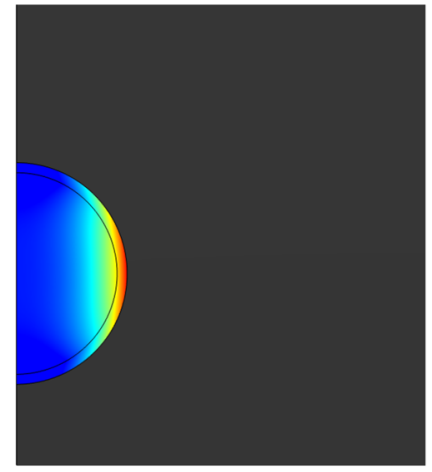

(a) $\mathrm{t}=60 \mathrm{~s}$

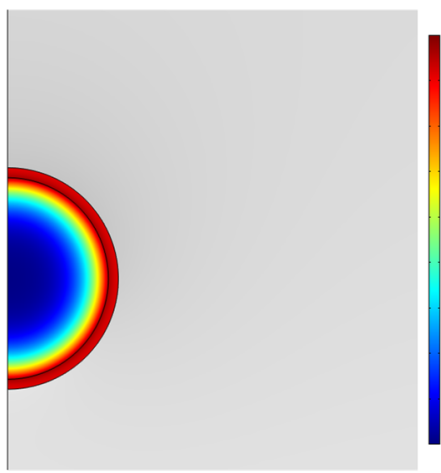

(d) $\mathrm{t}=60 \mathrm{~s}$

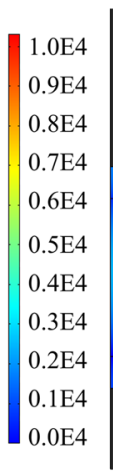

(0)

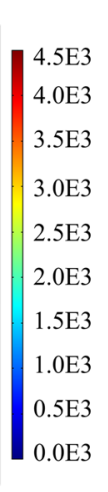

$4.5 \mathrm{E} 3$
$4.0 \mathrm{E} 3$
$3.5 \mathrm{E} 3$
$3.0 \mathrm{E} 3$
$2.5 \mathrm{E} 3$
$2.0 \mathrm{E} 3$
$1.5 \mathrm{E} 3$
$1.0 \mathrm{E} 3$
$0.5 \mathrm{E} 3$
$0.0 \mathrm{E} 3$

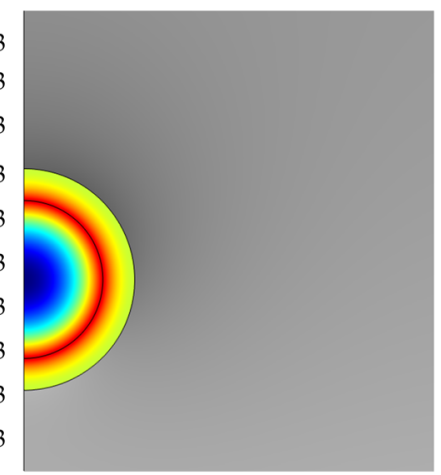

(e) $\mathrm{t}=300 \mathrm{~s}$

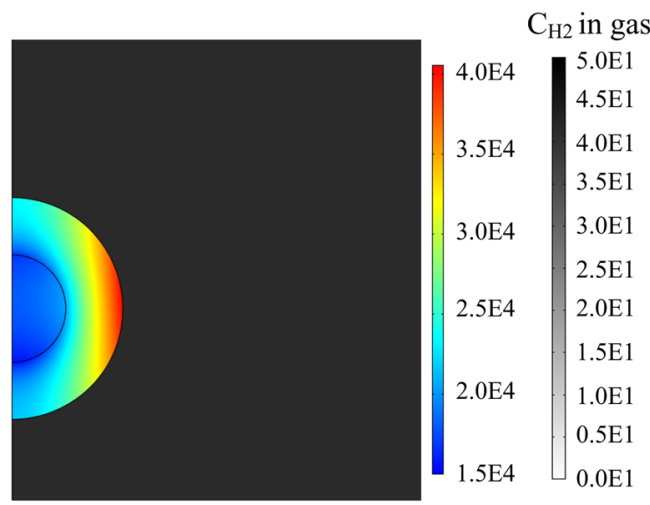

(c) $\mathrm{t}=600 \mathrm{~s}$
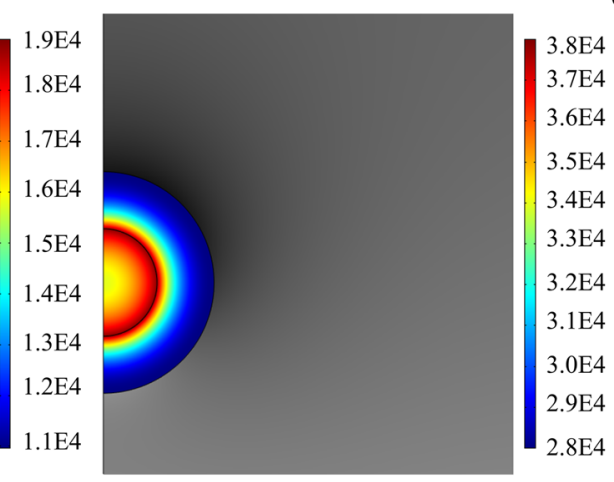

$\mathrm{C}_{\mathrm{H} 2 \mathrm{O}}$ in gas

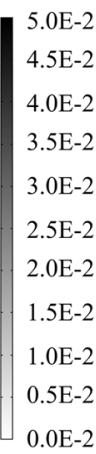

(f) $\mathrm{t}=600 \mathrm{~s}$

Fig. 6- The concentration profiles in the gas and solid domains for type-I pellets at $1123 \mathrm{~K}\left(850{ }^{\circ} \mathrm{C}\right)$; $(a)$, $(b)$ and $(c) \mathrm{H}_{2}$ concentrations $\left(\mathrm{mol} \mathrm{m} \mathrm{m}^{-3}\right),(d),(e)$ and $(f) \mathrm{H}_{2} \mathrm{O}$ concentrations $\left(\mathrm{mol} \mathrm{m}^{-3}\right)$. The color legends show the concentration ranges in the solid domains and the greyscale legends show the concentration ranges in the gas phase.

Table I. The Reaction Rates and Effective Diffusivities

\begin{tabular}{lccr}
\hline & & \multicolumn{2}{c}{$\mathrm{D}_{\text {eff, } \mathrm{H} 2\left(\mathrm{~m}^{2} \mathrm{~s}^{-1}\right)}$} \\
\cline { 3 - 4 } Temp. $\left[\mathrm{K}\left({ }^{\circ} \mathrm{C}\right)\right]$ & Reaction Rate $\left(\mathrm{s}^{-1}\right)$ & Type-I & Type-II \\
\hline $1073(800)$ & $2.34 \times 10^{-2}$ & $3.55 \times 10^{-8}$ & $4.1 \times 10^{-8}$ \\
$1123(850)$ & $2.62 \times 10^{-2}$ & $4.88 \times 10^{-8}$ & $14.05 \times 10^{-8}$ \\
\hline
\end{tabular}

atmospheric pressure. In the computational domains, no-slip boundary condition is considered for all walls. The temperature in the system is the reaction temperature.

The flux of hydrogen from the gas phase to the pellet, and the flux of produced water vapor from the pellet surface to the gas phase are the boundary conditions at the pellet-gas interface which connect the mass transfer between the solid and the gas stream. The walls of the reaction tube were considered as boundaries with no mass fluxes. The apparent rates of chemical reaction were obtained from an unpublished work by the present research group. ${ }^{[24]}$ In this study, $20 \mathrm{mg}$ of fine iron ore powder (a few $\mu \mathrm{m}$ in particle size) was kept in a very shallow crucible in a hydrogen stream of high flow rate. This arrangement would ensure that the reaction was controlled by chemical reaction at least at the initial stage of the reaction. The rates were estimated from the largest slope of reduction curves. The estimated values are presented in Table I.

The size and the shape of the meshes in the calculation domains were carefully selected due to the complexity of the connection between the moving boundary in the solid and the exchange of fluxes between gas and solid phases. Therefore, the MUMPS solver in COMSOL Multiphysics was used in the fully coupled calculations. Three meshes were tested for the calculations as listed in Table II. Mesh M2 was chosen for all calculations because it provided similar precision for the calculated reaction extents as the finer mesh, within a more appropriate solution time. An initial value of $D_{\text {eff }}$ for each sample was evaluated from the experimental result for reaction extent at 20 minutes, considering the reduction at this stage is mostly controlled by mass transfer of gases in the solid phase. Based on this initial value, the $D_{\text {eff }}$ was optimized by the model using curve 
fitting. The $D_{\text {eff }}$ values (reported in the table) are the mass transfer properties associated with different pellets.

\section{CALCULATION RESULTS AND DISCUSSION}

Figure 6 presents the concentration distributions of $\mathrm{H}_{2}$ and $\mathrm{H}_{2} \mathrm{O}$ in the solid and gas domains, calculated for type-I pellets at $1123 \mathrm{~K}\left(850{ }^{\circ} \mathrm{C}\right)$. The results show that the $\mathrm{H}_{2} \mathrm{O}$ produced at the reaction site diffuses into the unreacted core. Note that in most studies using shrinking core model, the presence of $\mathrm{H}_{2} \mathrm{O}$ in the oxide phase is not considered. The presence of $\mathrm{H}_{2} \mathrm{O}$ in the oxide phase affects the local equilibrium between solids and gases and influences the reduction rate.

The stream lines around the pellet are laminar, and the gas velocities are nearly constant with respect to time in the fluid domain, except the zone very near the gas inlet in the lower part of reaction tube. In fact, the gas velocity is nearly uniform in the whole reaction tube, showing that even in the area above the pellet no stagnant zone is formed. However, at low gas flow rates, it can be expected that significantly low velocities in some areas affect the distribution of gaseous species and therefore influence the equilibrium. Thus, it is essential to consider this factor in a larger scale process model due to more complex fluid flow in the reactor.

The concentration distributions of $\mathrm{H}_{2}$ and $\mathrm{H}_{2} \mathrm{O}$ in the solid and the surrounding gas phase are presented in Figure 6 at three different time intervals. The figure indicates that the concentration of hydrogen in the gas phase does not vary with time. The changes in $\mathrm{H}_{2} \mathrm{O}$ concentration in the gas phase are also rather small. It should be pointed out that when a single pellet is reacting in a gas stream with high concentration of $\mathrm{H}_{2}$, the concentration of $\mathrm{H}_{2} \mathrm{O}$ in the surrounding gas phase is low. However, in the larger scale processes, the amounts of gaseous products are larger and have a greater impact on the atmosphere. In addition, the gas composition varies at different heights of the shaft furnace. The concentration profiles of the reactants and products in Figure 6 highlight the importance of connecting the mass transfers in the gas phase and the solid phase to obtain reliable results for the concentration changes of all species during the process. It should be mentioned that $\mathrm{H}_{2} \mathrm{O}$ is produced from the chemical reaction taking place at the reaction interface with an axisymmetric rate, and therefore, the distribution of $\mathrm{H}_{2} \mathrm{O}$ is axisymmetric. Hydrogen is provided with high flow rate from the gas inlet placed in the bottom of the reaction tube. Therefore, the $\mathrm{H}_{2}$ flow in the gas phase has a large effect on hydrogen distribution in the solid. Although $\mathrm{H}_{2}$ is consumed in the pellet with an axisymmetric chemical reaction rate, the distribution of $\mathrm{H}_{2}$ is not axisymmetric during reduction.

The optimized $D_{\text {eff }}$ values for hydrogen in the two types of commercial pellets at the experimental temperatures are listed in Table I. Using the values in Table I, the degrees of reaction are calculated for type-I and type-II pellets by the model. The calculated $R_{\text {ex }}$ are plotted as a function of time in Figure 4 to compare with the experimental results. It is seen that the calculation results are in general in good agreement with the experimental data. The plots in Figure 4 illustrate that while the calculations predict the reaction extents of type-I and type-II pellets reasonably well, there are still some differences between the experimental reaction extents and the calculations. At the initial stages, the reduction rate is slightly higher in the calculated curves. The difference is slightly more in the case of type-II samples. The differences could be caused by assuming that the reaction takes place at the boundary of the unreacted core. On the other hand, as presented in Figure 3, the chemical reaction takes place in a layer. This aspect needs to be considered in further improvements of the model. Nevertheless, the present model could be a good basis for the development of a comprehensive process model.

In order to examine the role of chemical reaction in the process, a calculation was made for type-I pellet assuming the reaction was fast, so that the reaction always reached equilibrium. Figure 7 shows the comparison of the results from this calculation with the experimental data. The poor model prediction suggests that chemical reaction plays an important role almost in the whole process of reduction for the pellets having high porosity. This argument is supported by the morphology of the partially reduced sample shown in Figure 3(c). It is clearly seen that in the reaction zone, different oxides coexist. Neglecting the role of chemical reaction in the process model might lead to unsatisfactory results. Figures 4 and 7 indicate that coupling chemical reaction with diffusion and mass transfer in the model is necessary for process modeling.

Similar calculation procedure was applied to predict the reduction curve for type-III sample at $1123 \mathrm{~K}$ $\left(850^{\circ} \mathrm{C}\right)$. Note that, many efforts were made to obtain

Table II. Comparison of Different Meshes

\begin{tabular}{llll}
\hline Mesh & \multicolumn{1}{c}{ M1 } & M2 & M3 \\
\hline Total number of elements & 113084 & 61028 & 33508 \\
$R_{\text {ex }}$ at $t=600 \mathrm{~s}$ & 0.896 & 0.886 & 0.871 \\
\hline
\end{tabular}

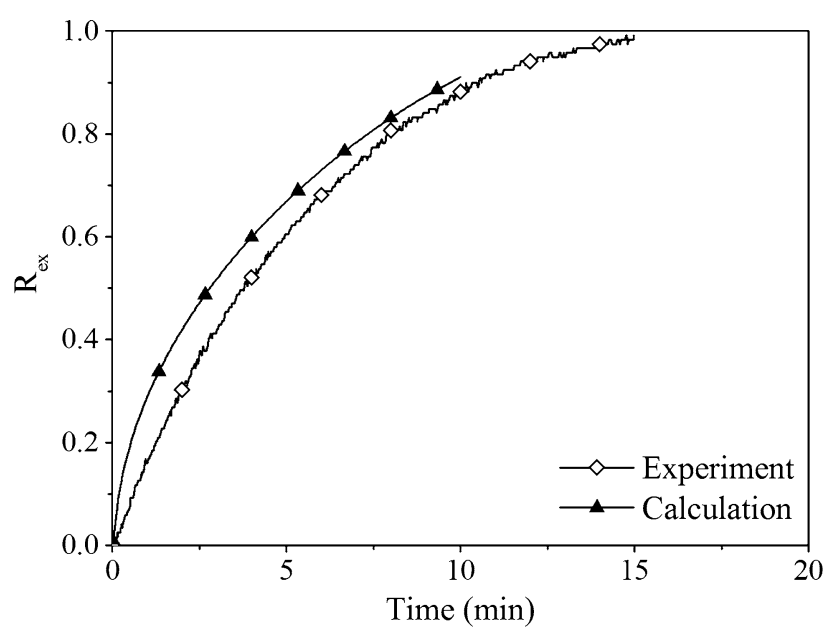

Fig. 7-The influence of reaction rate on the calculation results at $1123 \mathrm{~K}\left(850{ }^{\circ} \mathrm{C}\right)$ for type-I pellets. 
good curve fitting and the calculated curve plotted in Figure 8 is the best among all the tests. Large difference is seen between the calculated results and the experimental data. It can be concluded that the present model can only be applied to the pellets having reaction mechanism as type-I and type-II. Since the reaction of type-III pellet proceeds layer by layer (see Figure 2(c)), the present model cannot be applied. The unsatisfactory result from using the present model for type-III supports the argument that a model must take the type of pellets into consideration. It also encourages the present approach that the type of pellets should be considered in a sub-model, which can be incorporated into the process model as a module. The basic idea of the present modeling approach is to first identify the mechanism of the reduction. The $\mathrm{D}_{\text {eff }}$ values evaluated by the model based on the experiments could be considered as identification parameters for each type of pellets.

It should be mentioned that the reduction mechanism of layer by layer reduction $\left(\mathrm{Fe}, \mathrm{FeO}, \mathrm{Fe}_{3} \mathrm{O}_{4}\right.$, and $\left.\mathrm{Fe}_{2} \mathrm{O}_{3}\right)$ is evidently seen in the pellets made in the laboratory, type-III. On the other hand, the reduction of the commercial pellets (Type-I and Type-II) does not proceed according to this layer-by-layer mechanism. Since the objective of the present work is towards the development of a model for industrial reactor, the focus is given to the commercial oxide pellets. Therefore, no further attempt is made to model the dense pellets made in the laboratory, since the mechanism is very different with respect to the commercial ones.

It is also worthwhile to mention that the reduction is faster in type-II pellets due to their higher porosity compared to type-I pellets. However, the reduction mechanism for these two types of pellets is similar under the applied experimental conditions. The mechanical properties of the two types of pellets were found very different. They even behave differently with respect to cementite formation and carbon shooting. These differences are discussed in detail in a previous publication by some of the present authors. ${ }^{[25]}$

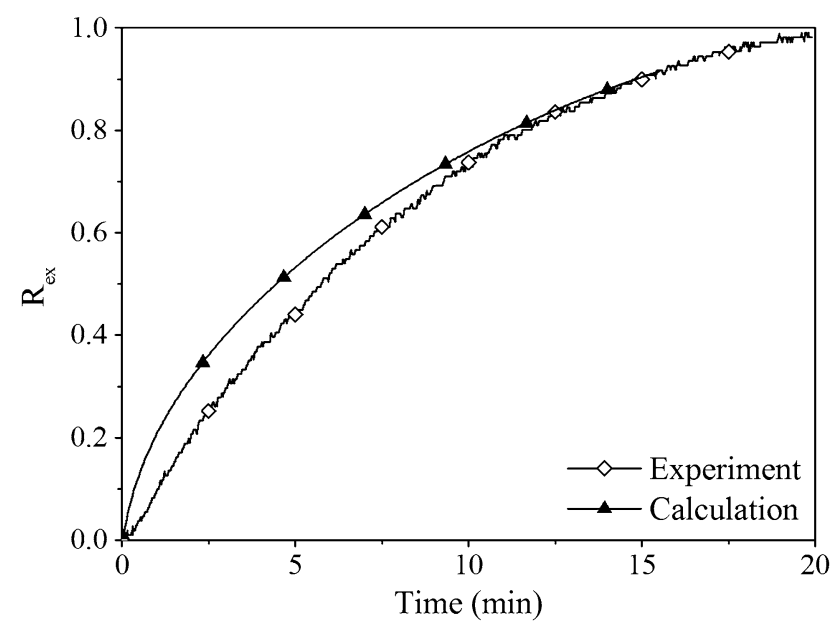

Fig. 8-The experimental and calculated results for type-III pellets at $1123 \mathrm{~K}\left(850^{\circ} \mathrm{C}\right)$.
Note that the assumption of constant temperature and isothermal condition in the model may cause problem in understanding of metal-sticking phenomena in industrial operation of a direct reduction process. The non-isothermal nature of the process must be considered in future development.

The present work presents a new approach in modeling the gaseous reduction process of a single oxide pellet by coupling and calculating multiple physics in one model. These physics are as follows: flow and mass transport in fluid calculated by computational fluid dynamics (CFD) approach, mass transport in the solid phases and heterogeneous chemical reaction in the reaction zone. This is the first time such a model has been developed for gaseous reduction process by applying a Multiphysics software for dynamic modeling of gaseous reduction of iron oxide. The coupling of mass transfer in the gas phase with the diffusion through the solid as well as the chemical reaction at the reaction sites has set up a good foundation for dynamic modeling of shaft reactor for reduction of iron ore. To the knowledge of the present authors, this is a pioneer effort. However, more work is needed to reach the goal of dynamic model considering the heat transfer and the chemical reaction rates at different temperatures which are significant factors in a model for multi-particle systems.

\section{SUMMARY}

Experiments were conducted to study the mechanisms of reduction of different hematite pellets by hydrogen gas. Three types of pellets were examined: two types from industry with porosities equaling to 26 and $34 \mathrm{pct}$, and one type prepared in the laboratory having high density. The reduction was followed as a function of time at two temperatures. While the type-I and type-II samples were found to have identical reaction mechanism, type-III had a different reduction mechanism.

In an original effort, a model was developed to couple mass transfer in the gas phase, gas diffusion in the solid and the chemical reaction at the reaction front to describe the isothermal reduction of single iron oxide pellets. The model was used to predict the degrees of reaction using the optimized effective diffusivity for different types of pellets. The computed results were in reasonably good agreement with the experimental data for the industrial pellets. The results also revealed that neglecting chemical reaction as a controlling step in the case of porous pellets might lead to unrealistic prediction of results.

The present work emphasized the importance of evaluation of the reduction mechanisms and the properties of different types of iron ore pellets prior to developing a process model. The connection between mass transfers in the gas atmosphere and solid phases, and the chemical reaction is necessary to calculate all the changes in the dynamic system simultaneously, and is essential for a process model. By addition of heat transfer to the current model and considering the changes in reduction mechanism caused by temperature, the model 
can be applied as a sub-model in a multi-particle process with varying temperature profile and atmosphere.

\section{ACKNOWLEDGMENTS}

The authors would like to thank Magnus Tottie and Lars Norrman for the invaluable discussions, suggestions, and comments. The financial support from LKAB is gratefully acknowledged.

\section{OPEN ACCESS}

This article is distributed under the terms of the Creative Commons Attribution 4.0 International License (http://creativecommons.org/licenses/by/4.0/), which permits unrestricted use, distribution, and reproduction in any medium, provided you give appropriate credit to the original author(s) and the source, provide a link to the Creative Commons license, and indicate if changes were made.

\section{REFERENCES}

1. A Bonalde A Henriquez M Manrique : ISIJ Int., 2005, vol. 45, pp. $1255-60$.

2. RH Tien and ET Turkdogan: Metall. Trans., 1972, vol. 3, pp. 2039-48.

3. QT Tsay, WH Ray, and J Szekely: AIChe J., 1976, vol. 22, pp. 1064-72.

4. J Bessières, A Bessières, and JJ Heizmann: Int. J. Hydrog. Energy, 1980, vol. 5, pp. 585-95.
5. K Piotrowski, K Mondal, $\mathrm{H}$ Lorethova, L Stonawski, T Szymanski, and T Wiltowski: Int. J. Hydrog. Energy, 2005, vol. 30, pp. 1543-54.

6. A Pineau, N Kanari, and I Gaballah: Thermochim. Acta, 2006, vol. 447 , pp. $89-100$.

7. DR Parisi and MA Laborde: Chem. Eng. J., 2004, vol. 104, pp. 35-43.

8. A Ranzani da Costa, D Wagner, and F Patisson: J. Cleaner Prod., 2013, vol. 46, pp. 27-35.

9. A Ajbar, K Alhumaizi, and M Soliman: Ironmak. Steelmak., 2011, vol. 38, pp. 401-11.

10. A. Shams and F. Moazeni, JOM, 2015, pp. 2681-89.

11. KO Yu and PP Gillis: Metall. Trans. B, 1981, vol. 12, pp. 111-20.

12. Y Takenaka and Y Kimura: Comput. Chem. Eng., 1986, vol. 10, pp. 67-75.

13. ED Negri, OM Alfano, and MG Chiovetta: Ind. Eng. Chem. Res., 1991, vol. 30, pp. 474-82.

14. ED Negri, OM Alfano, and MG Chiovetta: Ind. Eng. Chem. Res., 1995, vol. 34, pp. 4266-76.

15. MS Valipour, MY Motamed Hashemi, and Y Saboohi: $A d v$. Powder Technol., 2006, vol. 17, pp. 277-95.

16. SMM Nouri, H Ale Ebrahim E Jamshidi: Chem. Eng. J., 2011, vol. 166, pp. 704-9.

17. MVC Sastri, RP Viswanath, and B Viswanathan: Int. J. Hydrog. Energy, 1982, vol. 7, pp. 951-55.

18. RJ Fruehan, Y Li, L Brabie, and E-J Kim: Scand. J. Metall., 2005, vol. 34 , pp. 205-12.

19. ET Turkdogan and JV Vinters: Metall. Trans., 1971, vol. 2, pp. 3175-88.

20. D. Wagner, O. Devisme, F. Patisson, and D. Ablitzer: Sohn International Symposium on Advanced Processing of Metals and Materials, 2006, vol. 2, pp. 111-20.

21. M Kazemi, B Glaser, and D Sichen: Steel Res. Int., 2014, vol. 85, pp. $718-28$.

22. COMSOL Multiphysics ${ }^{\circledR}$ v. 5.1. www.comsol.com. COMSOL $\mathrm{AB}$, Stockholm, Sweden.

23. DR Poirier and GH Geiger: Transport Phenomena in Materials Processing, The Minerals, Metals and Materials Society, Warrendale, Pennsylvania, 1994.

24. M. Kazemi: KTH (Royal Institute of Technology), Stockholm, Sweden, 2016.

25. M Kazemi and Du Sichen: Metall. and Materials Trans. B, 2016, DOI:10.1007/s11663-016-0780-0. 